\title{
Role of the embryonic vesicle and progesterone in embryonic loss in mares
}

\author{
D. R. Bergfelt, J. A. Woods and O. J. Ginther* \\ Department of Veterinary Science, University of Wisconsin-Madison, Madison, WI 53706 USA
}

\begin{abstract}
Summary. Characteristics of spontaneous embryonic loss in 21 mares were compared with those of 52 contemporary mares that maintained pregnancy. Embryonic losses were, in retrospect, grouped according to day of loss and length of the interovulatory interval, respectively, as follows: group $1, \leqslant$ day 20 and $\leqslant 30$ days $(n=10)$; group 2 , $\leqslant$ day 20 and $>30$ days $(n=3)$; and group 3 , >day 20 and $>30$ days $(n=8)$; ovulation was day 0 . Mean diameter of the embryonic vesicle in group 1 was smaller $(P<0.05)$ on days $12-18$ than in the pregnancy-maintained group, but among the pregnancy-maintained group and the embryonic-loss groups, the mean individual growth rates of vesicles was similar (no significant difference). A more frequent $(P<0.05)$ location of the vesicles in the uterine body on day 13 in group 1 was due to a greater proportion of small vesicles and for day 18 was due to a greater incidence of fixation failure. Luteal regression occurred at the expected time in $77 \%$ of the mares with loss sooner than day 20 . Low concentration of progesterone on days 12,15 and 18 , a detected decrease in diameter of the corpus luteum on days 15 and 18 , and an interovulatory interval of $\leqslant 30$ days indicated that luteolysis was not prevented by the embryonic vesicle in group 1 . However, in mares in group 2, the corpus luteum was maintained as indicated by luteal diameters, progesterone concentrations, and prolonged interovulatory intervals. Thus, luteal maintenance occurred in $23 \%$ of mares with embryonic loss at $\leqslant$ day 20 . In group 3 (loss $>$ day 20 ), circulating concentrations of progesterone were either maintained (four mares) after embryonic death (cessation of embryonic heartbeat) or appeared to decrease before death (two mares) or on the day of death (one mare). The decrease in progesterone on the day of death seemed to be associated with acute endometritis. In another mare, embryonic loss was associated with continuing low concentrations of progesterone, a flaccid uterus, an oversized embryonic vesicle, failure of development of an embryo proper and collapse of the large vesicle on day 42 . The apparent drop in progesterone before embryonic death in two of eight mares with loss after day 20 could have been associated with primary luteal insufficiency.
\end{abstract}

Keywords: mare; embryonic loss; embryonic vesicle; progesterone; interovulatory interval

\section{Introduction}

Many factors have been associated with spontaneous embryonic loss in mares (reviews: Ball, 1988; Ginther, 1985a, 1986). Small embryonic vesicles during the embryo mobility phase (days 11-15) are indicators of increased probability of impending loss, even though growth rate is usually similar to that of normal-sized vesicles (Ginther et al., 1985, 1986; Woods et al., 1990). Embryos that are lost are more frequently located in the uterine body during the mobility phase (Ginther, 1986). This was due to the small diameter, since normal vesicles of a corresponding diameter (days 9-11) are more

*Reprint requests. 
frequently found in the uterine body (Leith \& Ginther, 1984). Reduced concentrations of progesterone have been associated with spontaneous embryonic loss in mares and could involve (Ginther, 1985a; Adams et al., 1987) (i) induced luteolysis due to endometritis, (ii) failure of the conceptus to block luteolysis, or (iii) primary luteal insufficiency. After spontaneous embryonic loss, the primary corpus luteum was maintained more often when loss occurred after day 20 than when loss occurred before day 20 (Ginther et al., 1985). The roles of the embryonic vesicle and circulating progesterone concentrations in association with embryonic loss have not been described adequately in relation to the day of loss.

It has been reported (Bergfelt et al., 1989) that resurgence of the primary corpus luteum (increase in size and progesterone production) occurs between days 35 and 40 of pregnancy and is attributable to the release of equine chorionic gonadotrophin into the circulation. Presumably, the corpus luteum that was subsequently maintained in mares with embryonic loss would not increase in size provided loss occurred before invasion of trophoblastic cells into the endometrium with resulting production of equine chorionic gonadotrophin.

The present study characterized a group of spontaneous embryonic losses in mares. The following characteristics were studied in relation to day of loss: (i) diameter, location and ultrasonic appearance of the embryonic vesicle, (ii) diameter of the primary corpus luteum, (iii) circulating concentrations of progesterone and (iv) length of interval to subsequent ovulation. To examine further the phenomenon of resurgence of the primary corpus luteum during pregnancy, the diameter of the corpus luteum and circulating concentrations of progesterone were compared between mares that maintained pregnancy and mares that maintained the corpus luteum after embryonic loss.

\title{
Materials and Methods
}

\begin{abstract}
Animals
Characteristics of 21 mares (individually identified as mares A U) with spontaneous embryonic loss were compared with those of 52 contemporary mares that maintained pregnancy. The mares were primarily large ponies and pony $\times$ horse crosses that were mated as part of a previous study (Woods et al., 1990). Mares were $\geqslant 3$-years old, but age was not studied as a factor. Mares were free of ultrasonically detectable uterine pathology (dioestrous intrauterine fluid collections, extensive cysts) before entering the insemination programme, which has been described (Woods et al., 1990).
\end{abstract}

\section{Ultrasonic examinations}

Examinations were made transrectally with a real-time ultrasound scanner equipped with a linear-array $5.0 \mathrm{MHz}$ transducer (Woods et al., 1990). Daily ultrasound examinations were done from day 10 to day 15 (ovulation was day $0)$. Pregnancy was defined as an increase in diameter or a change in intrauterine location of an apparent embryonic vesicle over 2 consecutive days. After day 15, pregnant mares were examined every 3 days until day 48 . At each ultrasonic examination, the following were evaluated: (i) diameter of the embryonic vesicle (average of height and width) and (ii) location of vesicle (uterine horns or body). The diameter of the corpus luteum (average of height and width) was recorded. Measurements of the corpus luteum were taken from an image of its largest cross-section, excluding the neck-like process leading to the ovulation fossa. If a central blood clot was observed (Ginther \& Pierson, 1985), its diameter was determined separately and subtracted from the overall diameter. This was done to adjust for an overall luteal diameter with those luteal glands that did not develop a central blood clot.

The following were used as indicators of impending embryonic loss (Ginther, 1985b): (i) a notable decrease in size or failure to detect ultrasonically the primary corpus luteum, (ii) a change in uterine echotexture from dioestrus-like to oestrus-like, (iii) failure of fixation of the embryonic vesicle by day 18 (Ginther, 1986), or (iv) dislodgement of the vesicle after apparent fixation. Daily examinations were either continued or initiated if one or more of these indicators was observed during the previous examination. When embryonic loss occurred before detection of an embryonic heartbeat, the day of loss was defined as the day of disappearance of the embryonic vesicle. After detection of a heartbeat (mean, day 21), the day of embryonic loss was defined as the first day on which the heartbeat was no longer detected.

After embryonic loss, mares continued to be examined once every 3 days or daily (diameter of the largest follicle $\geqslant 25 \mathrm{~mm}$ ) until reovulation. The following were recorded: (i) diameter of the largest follicle, (ii) diameter of the corpus luteum, (iii) occurrence of apparent collapse of the embryonic vesicle and (iv) occurrence of ovulation. In relation to 
an apparently intact vesicle during the previous examination, the day of collapse of a vesicle was defined as follows: (i) dramatic decrease in vesicle diameter, (ii) fluid accumulation in the uterine lumen and (iii) mass of free-floating debris within the fluid collection.

Table 1. Mean ( \pm SEM) day of loss of the embryonic vesicle and length of the interovulatory interval for mares in groups 1-3

\begin{tabular}{|c|c|c|c|c|c|}
\hline \multirow[b]{2}{*}{ Group } & \multirow[b]{2}{*}{ Mare } & \multicolumn{2}{|c|}{ Criteria for groups } & \multirow[b]{2}{*}{$\begin{array}{l}\text { Day } \\
\text { of loss }\end{array}$} & \multirow{2}{*}{$\begin{array}{l}\text { Length of } \\
\text { interovulatory } \\
\text { interval } \\
\text { (days) }\end{array}$} \\
\hline & & $\begin{array}{l}\text { Day } \\
\text { of loss }\end{array}$ & $\begin{array}{l}\text { Interovulatory } \\
\text { interval (days) }\end{array}$ & & \\
\hline 1 & $\begin{array}{c}\mathrm{A}-\mathrm{J} \\
(n=10)\end{array}$ & $\leqslant$ day 20 & $\leqslant 30$ & $\begin{array}{c}17.6 \pm 0.6(n=10) \\
\quad(\text { range }, 15-20)\end{array}$ & $\begin{array}{c}22 \cdot 8 \pm 1 \cdot 1(n=10) \\
\quad(\text { range }, 19-30)\end{array}$ \\
\hline 2 & $\begin{array}{c}\mathrm{K}-\mathrm{M} \\
(n=3)\end{array}$ & $\leqslant$ day 20 & $>30$ & $\begin{array}{c}15 \cdot 0 \pm 2 \cdot 0(n=3) \\
\quad(\text { range, } 13-19)\end{array}$ & $\begin{array}{c}70 \cdot 3 \pm 6 \cdot 3(n=3) \\
\quad(\text { range }, 58-79)\end{array}$ \\
\hline 3 & $\begin{array}{c}\mathrm{N}-\mathrm{U} \\
(n=8)\end{array}$ & $>$ day 20 & $>30$ & $\begin{array}{c}30 \cdot 6 \pm 0.8(n=7)^{\mathrm{b}} \\
(\text { range, } 29-35)\end{array}$ & $\begin{array}{c}71 \cdot 5 \pm 8.9(n=6)^{\mathrm{c}} \\
\quad(\text { range, } 54-115)\end{array}$ \\
\hline
\end{tabular}

${ }^{2}$ Defined as vesicle disappearance (loss $\leqslant$ day 20 ) or cessation of embryonic heartbeat (loss $>$ day 20 ).

${ }^{b}$ The embryonic vesicle of mare $U$ did not develop a detectable embryo proper and data for day of loss and interval from heartbeat cessation to vesicle collapse were not available. In group 3 the interval from heartbeat cessation to vesicle collapse was $12 \cdot 0 \pm 2 \cdot 8$ days (range, $0-21 ; n=7$ ).

${ }^{\mathrm{C}} \mathrm{Mares} \mathrm{N}$ and $\mathrm{T}$ were diagnosed anovulatory and were excluded.

\section{Study groups and end points}

A mare was considered anovulatory if reovulation or a new corpus luteum was not detected, the interval from embryonic loss exceeded 72 days, and the anovulatory season (after 15 October) had begun in barren mares. Mares in which embryonic loss was not detected were defined as the pregnancy-maintained group. Mares with embryonic loss were, in retrospect, grouped according to day of loss and length of the interovulatory interval, respectively, that encompassed the loss as follows: group 1 , $\leqslant$ day 20 and $\leqslant 30$ days (mares A-J); group 2 , $\leqslant$ day 20 and $>30$ days (mares K-M); and group 3, >day 20 and $>30$ days (mares $\mathrm{N}-\mathrm{U}$ ). The embryonic-loss groups were compared with the pregnancy-maintained group for the following: (i) diameter of the embryonic vesicle, (ii) frequency of location of the embryonic vesicle in the uterine body, (iii) circulating concentrations of progesterone and (iv) diameter of the corpus luteum.

\section{Embryonic vesicle}

To define whether an embryonic vesicle was normal, oversized or undersized, standard data were prepared from the 52 mares in the pregnancy-maintained group. The mean vesicle diameter $( \pm 2 \mathrm{sD})$ was calculated daily for days 12 , $13,14,15$ and 18. The vesicle diameter for each mare in the pregnancy-maintained and the embryonic-loss groups was compared with the standard data. On any day, an oversized or undersized vesicle was defined as $\geqslant 2 \mathrm{SD}$ above or below the mean, respectively; the probability of oversize or undersize of an individual vesicle on any day by chance alone was $2.5 \%$ for each condition. Mean growth rate $\left(\mathrm{mm} \mathrm{day}^{-1}\right)$ of the embryonic vesicle during days $12-15$ was compared between the pregnancy-maintained and the embryonic-loss groups.

\section{Progesterone and corpus luteum}

A blood sample was taken for progesterone analysis beginning on the first day an embryonic vesicle was detected and continued once every 3 days until day 48 (pregnancy-maintained group) or until reovulation (embryonic-loss groups). Concentrations of progesterone were determined using a modified, solid-phase ${ }^{125}$ I-labelling radioimmunoassay kit for progesterone (Coat-A-Count progesterone: Diagnostic Products Corporation, Los Angeles, CA, USA). The modification involved the use of progesterone standards prepared in ovariectomized mare plasma rather than in human plasma. This modification has previously been validated for use in this laboratory (Bergfelt \& Ginther, 1986). Sensitivity of the assay ranged from 0.1 to $0.2 \mathrm{ng} \mathrm{ml}^{-1}$ of plasma. The intra- and interassay coefficients of variation were 12 and $17 \%$, respectively. Progesterone concentrations were profiled for each mare that had maintained the corpus luteum after embryonic loss (groups 2 and 3). To examine the relationship between progesterone concentration relative to cessation of embryonic heartbeat, we prepared a standard profile from mares that maintained pregnancy. The profile consisted of the mean $\pm 2 \mathrm{sD}$ for each 3-day period, 12 days before and after the mean day of embryonic heartbeat cessation. Cessation of embryonic heartbeat was detected in group 3 on mean day 31 (range, 29-35). Each of the individual profiles for mares in group 3 was normalized to the mean day of heartbeat cessation. 

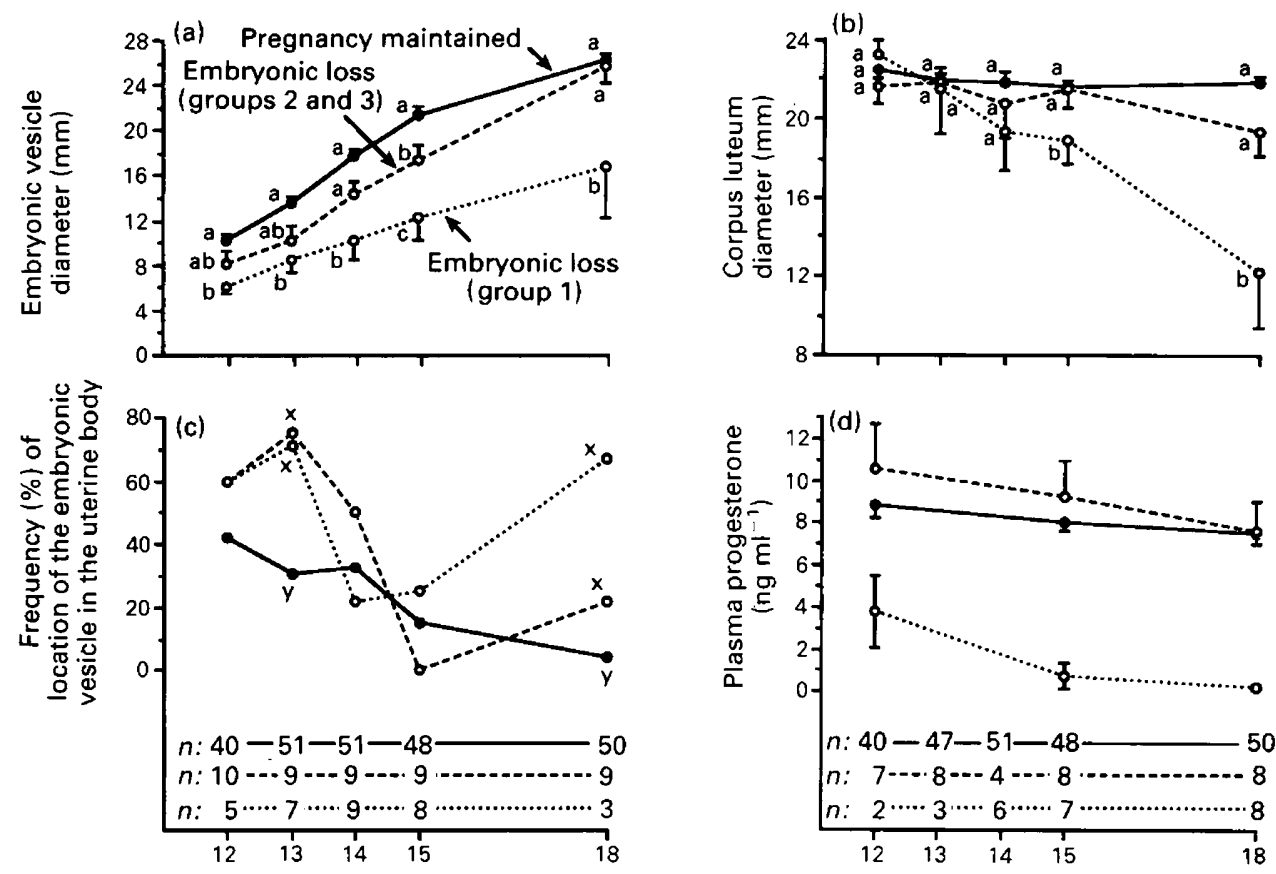

Number of days after ovulation

Fig. 1. Changes in (a) diameter of the embryonic vesicle, (b) diameter of the corpus luteum, (c) frequency of location of the embryonic vesicle in the uterine body and (d) concentration of progesterone in the pregnancy-maintained ( - ) and three embryonic-loss groups of mares, group $1(\cdots)$ and groups 2 and 3 combined $(---)$. There was a main effect of group $(P<0.001)$ for diameter of the embryonic vesicle and concentrations of progesterone and a group $\times$ day interaction $(P<0.0001)$ for diameter of the corpus luteum. A main effect of day $(P<0.0002)$ was also indicated for the three end points $(\mathrm{a}, \mathrm{b}$ and $\mathrm{d})$. Mean differences among groups on each of days $12,13,14,15$ and 18 are indicated by a superscript ( ${ }^{\mathrm{a}, \mathrm{b}}$ Duncan's multiple-range test and ${ }^{x, y} \chi^{2}$ analysis); $n$ : number of mares for each mean.

Table 2. Proportion of undersized vesicles ${ }^{\mathbf{a}}$ on each of days $12-15$ and 18 in the pregnancy-maintained and the embryonic-loss groups of mares; percentages in parentheses

\begin{tabular}{|c|c|c|c|c|c|}
\hline \multirow[b]{2}{*}{ Group } & \multicolumn{5}{|c|}{ Days } \\
\hline & 12 & 13 & 14 & 15 & 18 \\
\hline $\begin{array}{l}\text { Pregnancy-maintained } \\
\text { Embryonic-loss }\end{array}$ & $1 / 40$ & $1 / 51$ & $1 / 51(2)^{x}$ & $1 / 48(2)^{x}$ & $0 / 50(0)^{x}$ \\
\hline 1 & $1 / 5 \quad(20)$ & $1 / 7$ & $4 / 9 \quad(44)^{y}$ & $4 / 8 \quad(50)^{y}$ & $3 / 5 \quad(60)^{y}$ \\
\hline 2 & $0 / 3 \quad(0)$ & $0 / 1 \quad(0)$ & $0 / 1 \quad(0)$ & $1 / 1 \quad(100)$ & $1 / 1 \quad(100)$ \\
\hline 3 & $0 / 7 \quad(0)$ & $0 / 8 \quad(0)$ & $1 / 8 \quad(12)$ & $0 / 8 \quad(0)$ & $0 / 8 \quad(0)$ \\
\hline Total for groups 2 and 3 & $0 / 1 \quad(0)$ & $0 / 9 \quad(0)$ & $1 / 9(11)^{x y}$ & $1 / 9 \quad(11)^{x y}$ & $1 / 9 \quad(11)^{x y}$ \\
\hline
\end{tabular}



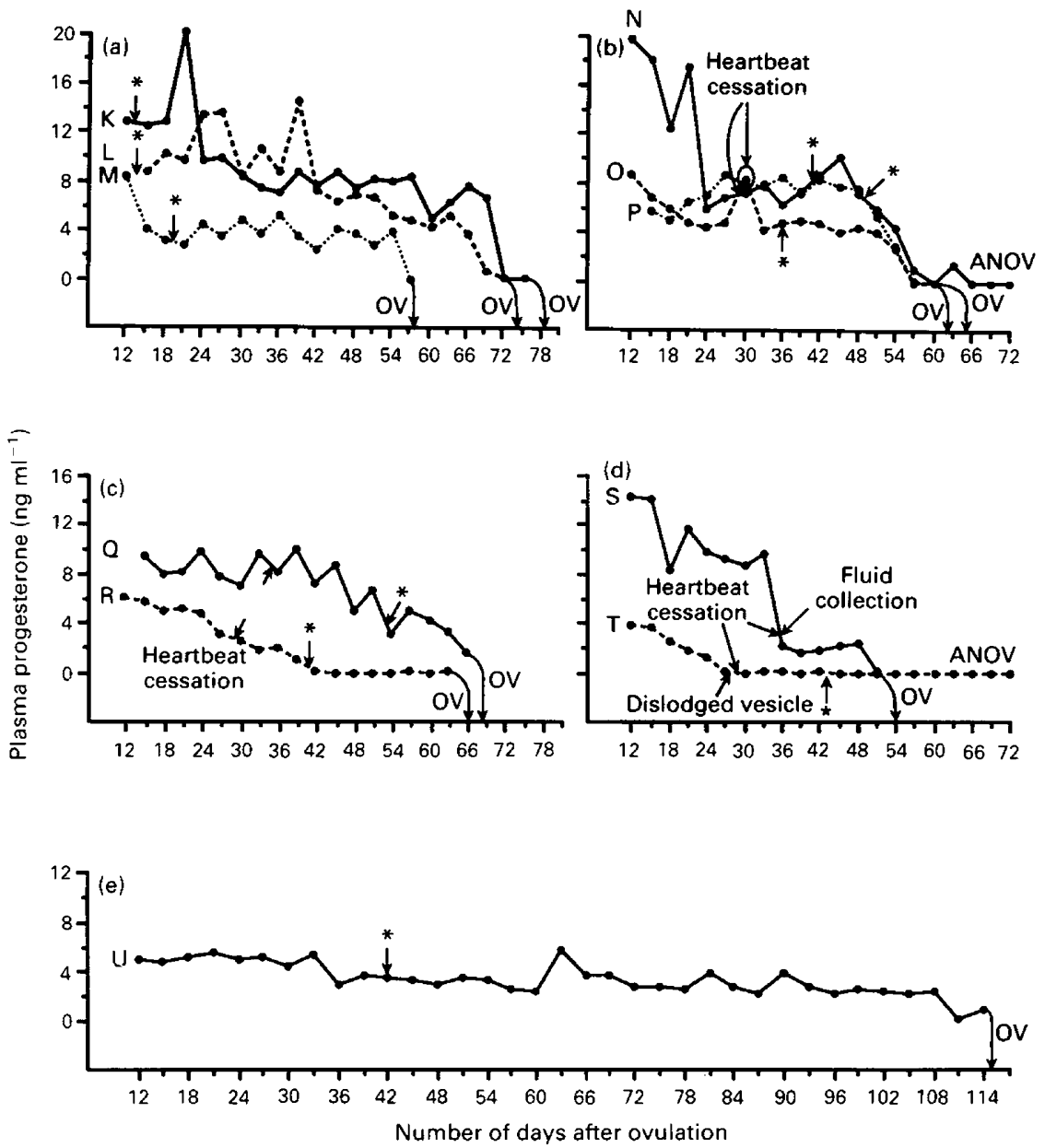

Fig. 2. Individual profiles of progesterone concentration in mares with embryonic loss in (a) group 2 (mares $\mathrm{K}-\mathrm{M}$ ) and (b-e) group 3 (mares $\mathrm{N}-\mathrm{U}$ ). The day of disappearance or collapse of vesicle $\left({ }^{*}\right)$, heartbeat cessation, fluid accumulation (apparently from acute inflammation), dislodgement of vesicle and subsequent ovulation $(\mathrm{OV})$ are indicated. Mares $\mathrm{N}$ and $\mathrm{T}$ were diagnosed anovulatory (ANOV) on day 72.

To determine whether resurgence of the primary corpus luteum occurred during pregnancy, but not during maintenance of the corpus luteum after embryonic loss (groups 2 and 3), we compared the diameter of the corpus luteum and circulating concentrations of progesterone during days $21-48$. Corpus luteum and progesterone data were not used after the first day of detection of secondary or accessory corpora lutea in any of the mares in the pregnancy-maintained group. In the embryonic-loss groups, data were not used after progesterone concentrations had decreased to $\leqslant 1 \cdot 0 \mathrm{ng} \mathrm{ml}^{-1}$.

\section{Statistical analyses}

A split-plot analysis of variance for repeated measures was used, with day and group (pregnancy-maintained group and embryonic-loss groups) as factors to evaluate the diameter of the embryonic vesicle, diameter of the primary corpus luteum and circulating concentrations of progesterone. Groups 2 and 3 were combined for these end points, because of the small number of mares in each group. Growth rate of the embryonic vesicle was determined separately for each mare from the slope generated by a linear regression; day was the independent variable and vesicle diameter was the dependent variable. Mean growth rate was determined for each group and comparison among groups was by analysis of variance. In mares that maintained the corpus luteum after embryonic loss, a simple linear regression was used to describe the degree of linearity associated with eventual decrease in diameter of the corpus luteum and concentrations of progesterone. Duncan's multiple-range test was used to locate differences in means 


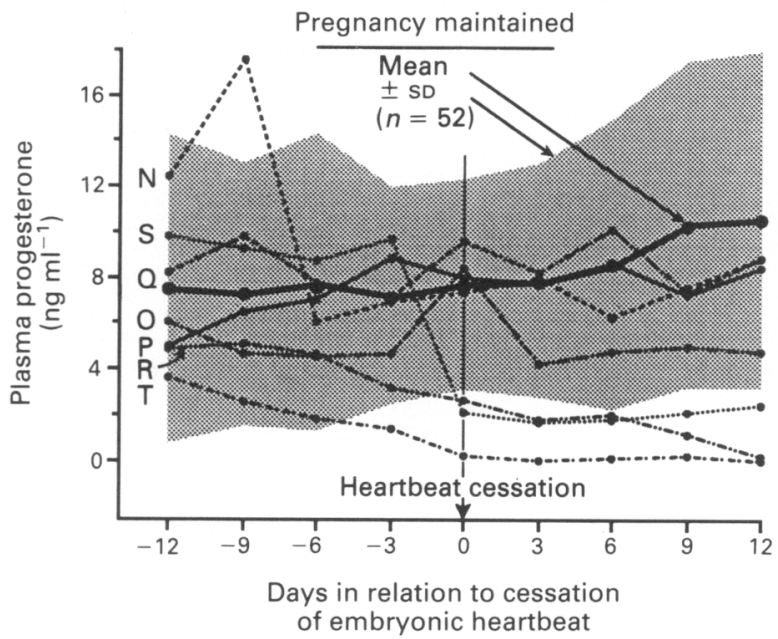

Fig. 3. Individual profiles of progesterone concentrations in seven mares with embryonic loss in group 3 (mares $\mathrm{N}-\mathrm{T}$ ) compared with a standard profile of concentrations in the pregnancymaintained group. The embryonic vesicle of mare $\mathbf{U}$ did not develop a detectable embryo proper and is not shown. Concentrations in the embryonic-loss group were normalized to the mean day of embryonic heartbeat cessation (day 31 ).

among all groups. A paired $t$ test was used to locate differences between 2 days within a group and an unpaired $t$ test was used to locate differences between two groups within a day. Chi-square analyses were used to evaluate the proportion of undersized embryonic vesicles and the frequency of location of the embryonic vesicle in the uterine body in the pregnancy-maintained group versus the embryonic-loss groups, group I and combined groups 2 and 3.

\section{Results and Discussion}

Embryonic loss occurred most frequently $\leqslant$ day $20(10$ of $21 ; 48 \%)$ and resulted in an interovulatory interval of $\leqslant 30$ days (group 1 , Table 1). The mean diameter of the embryonic vesicles in this group was significantly smaller on each of days $12,13,14,15$ and 18 than in the pregnancymaintained group but the mean of the individual growth rates was not different (Fig. la; overall mean $3.7 \mathrm{~mm} \mathrm{day}^{-1}$ ). More vesicles were classified as undersized in group 1 (Table 2) and were more often located in the uterine body (significant on day 13; Fig. 1c), compared with the pregnancymaintained group. Smaller diameters with normal growth rates, increased incidence of undersized vesicles (Ginther et al., 1985), and more frequent location in the uterine body (Ginther, 1986) during the mobility phase (days 12-15) for embryonic vesicles lost $\leqslant$ day 20 have been reported. In the previous studies, similarity of individual growth rates was based on visual inspection of data; this interpretation, however, was confirmed in the present study using regression analyses. Undersize of vesicles and more frequent location in the uterine body may be related phenomena. Embryonic vesicles in mares without embryonic loss were more frequently located in the uterine body on days 9-11 and this was believed to be related to a small diameter (Leith \& Ginther, 1984).

Failure of blockage of the uterine luteolytic mechanism by the embryonic vesicle (Ginther, 1986) in group 1 was indicated by an interovulatory interval $\leqslant 30$ days (mean, 22.8 days; Table 1), reduced progesterone concentrations on days 12,15 and 18 and reduced diameter of the corpus luteum on days 15 and 18 (Fig. $1 \mathrm{~b}$ and d). These results are compatible with either of the following interpretations: (i) undersized and apparently less mobile embryonic vesicles (more frequent location in the uterine body) were less likely to block the uterine luteolytic mechanism or (ii) undersized vesicles could block luteolysis, but other overriding factors activated the luteolytic mechanism (Ginther, 1985a; Adams et al., 1987). 

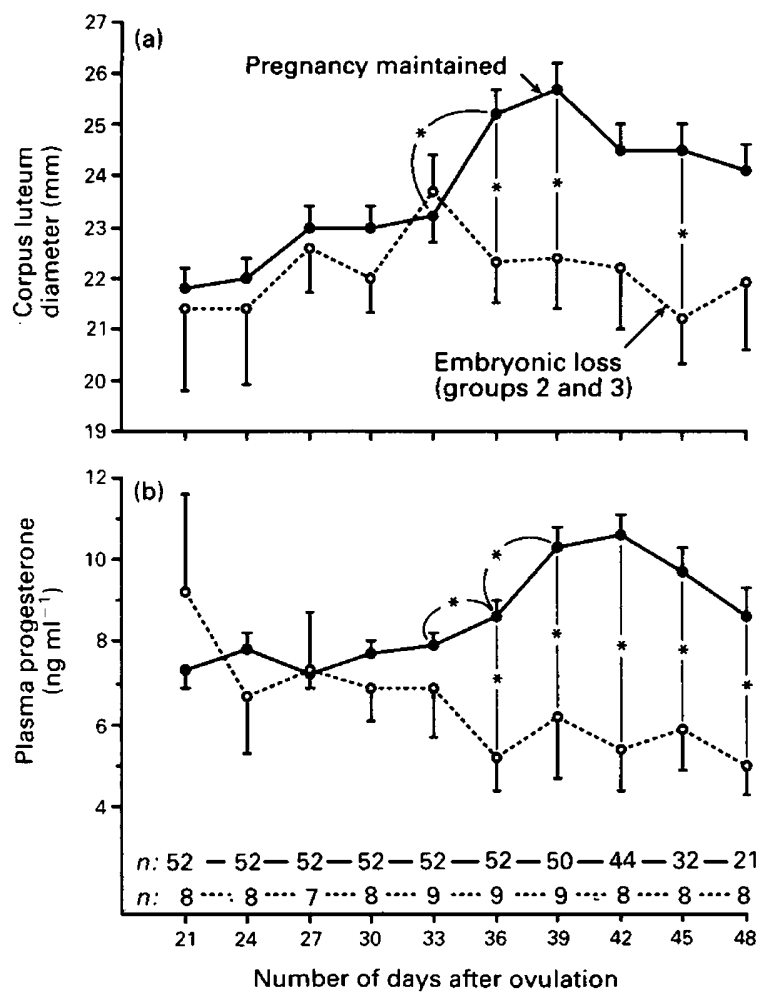

Fig. 4. Changes (mean \pm SEM) in (a) diameter of the primary corpus luteum and (b) circulating concentrations of progesterone during days $21-48$ for the pregnancy-maintained $(-)$ and the embryonic-loss $((\cdots)$ groups 2 and 3$)$ groups of mares. There was a main effect of group $(P<0.04)$ and day $(P<0.04)$ and an interaction of group $\times$ day $(P<0.0001)$ for diameter of the corpus luteum and concentrations of progesterone. Mean differences $\left({ }^{*} P<0.05\right)$ between groups within a day and within a group between days are indicated, $n=$ number of mares for each mean.

A minority (three of $13 ; 23 \%$ ) of the losses $\leqslant$ day 20 were associated with maintenance of the corpus luteum as indicated by luteal diameters, progesterone concentrations, and prolonged interovulatory intervals (group 2; Fig. 2a). These results are consistent with a previous study in which $29 \%$ of 41 losses $\leqslant$ day 20 were associated with luteal maintenance (Ginther et al., 1985). The three embryonic vesicles in group 2 were lost on days 13,13 and 19. Apparently, the vesicle or remnants or products of the vesicle lingered long enough to block the uterine luteolytic mechanism. In this regard, vesicles that are manually ruptured on days 12-14 (Ginther, 1983) or trophoblastic vesicles inserted on day 10 (Ball et al., 1989) can also block luteolysis. Perhaps embryonic vesicles lost during days $12-15$ can successfully block luteolysis if no other factors are present to override the antiluteolytic effect (Ginther, 1985a; Adams et al., 1987). In one of the three mares (M; Fig. 2a), circulating concentrations of progesterone declined at the time of loss and then maintained a plateau of lower concentrations that were adequate to delay a return to oestrus; this phenomenon has been observed previously (Ginther, 1986).

There were no firm indications of decreased diameter or increased frequency of undersized vesicles in group 2 (Table 2), but the number of mares was too small to permit adequate evaluation. However, when groups 2 and 3 were combined, there was an indication of smaller mean diameters on days 12-15 (significant on day 15; Fig. 1a). In addition, the vesicles were significantly more often located in the uterine body on day 13 (Fig. 1c). Perhaps, therefore, some of the vesicles in groups 2 

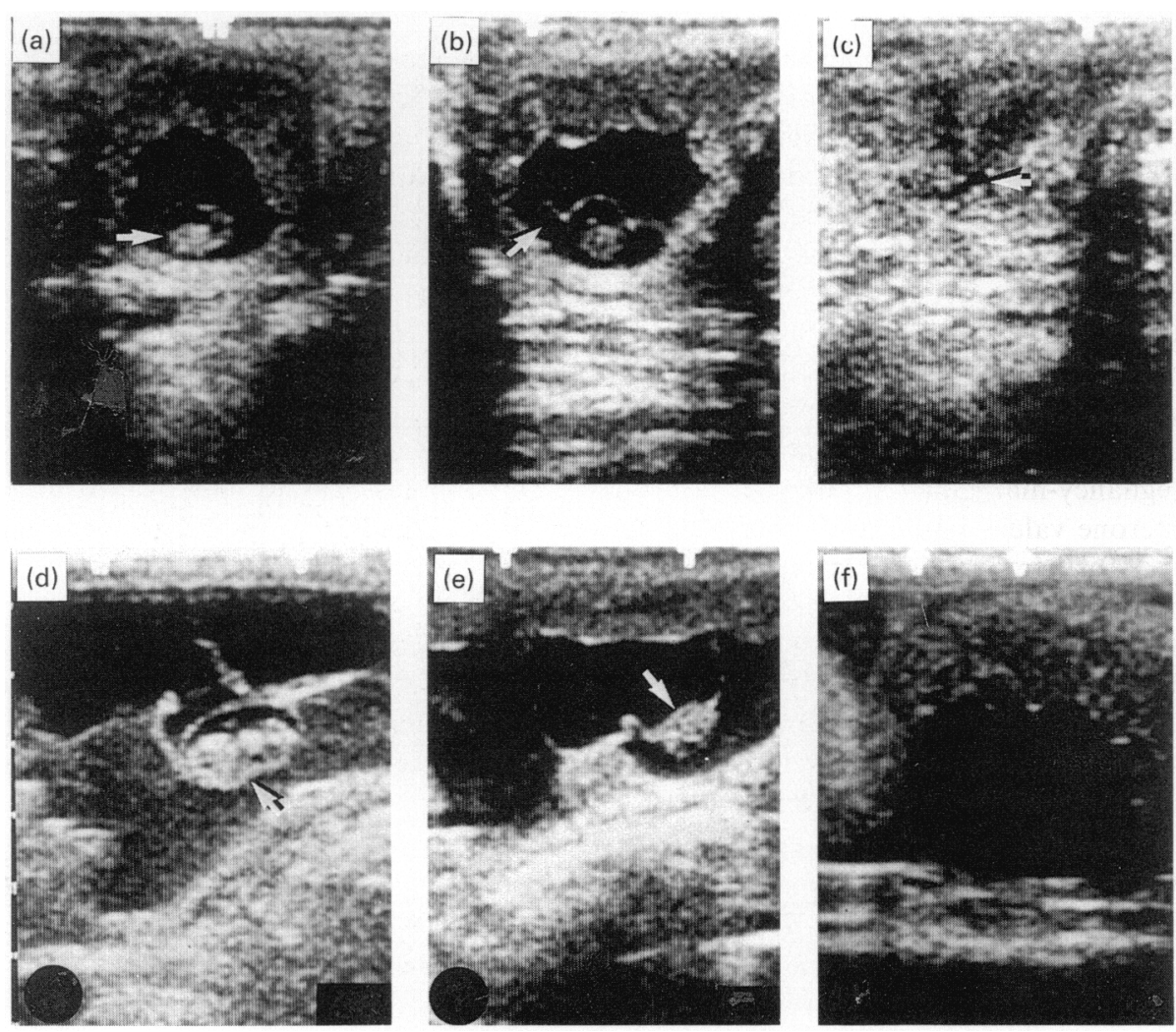

Fig. 5. Ultrasonograms of the embryonic vesicle for mare R on (a) day 29 (b) day 36 and (c) day 41, mares (d) S on day 35 (e) T on day 28 and (f) U on day 34. (a) Embryo (arrow) was detected without a heartbeat; (b) embryonic vesicle appeared underdeveloped with a small allantoic sac (arrow); (c) vesicle apparently collapsed leaving an accumulation of intrauterine fluid in the uterine body with free-floating debris (arrow); (d) embryo (arrow) was detected without a heartbeat; (e) embryonic vesicle became dislodged and was detected in the uterine body, the embryo (arrow) had a heartbeat on day 28 , but none was detected on day 29 ; and (f) embryo proper was not detected at any time and the embryonic vesicle was oversized; loss (collapse) occurred on day 42 .

and 3 were underdeveloped on days $12-15$ even though the corpus luteum was maintained and embryonic loss for group 3 did not occur until after day 20.

Failure of fixation (cessation of embryo mobility; Ginther, 1986) was indicated by a more frequent location of the vesicle in the uterine body on day 18 in the embryonic-loss groups, especially in group 1 (Fig. 1c). Perhaps failure of fixation was due to lack of adequate uterine tone and vesicle size (Ginther, 1986); however, uterine tone was not assessed in this study.

Circulating concentrations of progesterone in mares with embryonic loss in group 3 were maintained in four mares $(\mathrm{N}-\mathrm{Q})$ after embryonic death (cessation of heartbeat), appeared to decrease before death (mares $\mathrm{R}$ and $\mathrm{T}$ ), appeared to decrease on the day of death (mare $\mathrm{S}$ ), or seemed chronically low (mare U; Fig. 2b-e). Reduced progesterone concentration, as a result of primary luteal insufficiency, has not been adequately documented as a cause of embryonic loss in the mare. Recently, data on progesterone concentrations in mares losing pregnancy between days 17 and 42 were reported (Irvine $e t$ al., 1990). In 14 of 17 (82\%) mares losing pregnancy, progesterone concentrations did not decline until after pregnancy was lost and in one mare an apparent decline preceded loss. It was concluded that a fall in progesterone was a rare cause of pregnancy loss. In the present 
study, progesterone concentrations dropped $>2$ sD below the mean 3 days before heartbeat cessation in mare $T$ and on the day of heartbeat cessation in mares $R$ and $S$ (Fig. 3), whereas in mares $\mathrm{N}, \mathrm{O}, \mathrm{P}$ and $\mathrm{Q}$ concentrations were well within $2 \mathrm{SD}$ of the mean before and after heartbeat cessation. The decrease in progesterone in mare $S$ may have been associated with inflammation, and the apparent drop in progesterone before embryonic death in mares $\mathrm{R}$ and $\mathrm{T}$ could have been associated with primary luteal insufficiency; however, other contributing factors cannot be excluded (i.e. conceptus or uterine abnormalities). Selected ultrasonograms for the embryonic vesicles of mares R-U (group 3) are shown (Fig. 5).

The diameter of the primary corpus luteum and circulating concentrations of progesterone were greater on day 36 in mares that maintained pregnancy than in mares with embryonic loss (Fig. $4 a, b)$. The difference was attributable to resurgence of the primary corpus luteum after day 33 in the pregnancy-maintained group, but not in the embryonic-loss groups. The corpus luteum and progesterone values significantly increased between days 33 and 36 in the pregnancy-maintained group. A further significant increase in progesterone occurred between days 36 and 39 . In combined groups 2 and 3 , a linear $\left(R^{2}=0.58 ; P<0.05\right)$ decrease in diameter of the corpus I: 'eum occurred between days 33 and 48, whereas circulating concentrations of progesterone decreased linearly $\left(R^{2}=0.66 ; P<0.0003\right)$ between days 21 and 48 . The present results support the hypothesis (Bergfelt et al., 1989) that resurgence of the primary corpus luteum occurs in mares during pregnancy between days 35 and 40 and is a response to the release of equine chorionic gonadotrophin into the circulation.

This study was supported by the College of Agricultural and Life Sciences, University of Wisconsin-Madison and EquiCulture, Inc., Cross Plains, Wisconsin. The authors thank L. Kulick for technical assistance with the progesterone assay, data handling and preparation of graphs and M. Westphal for manuscript preparation.

\section{References}

Adams, G.P., Kastelic, J.P., Bergfelt, D.R. \& Ginther, O.J. (1987) Effect of uterine inflammation and ultrasonically detected uterine pathology on fertility in the mare. Journal of Reproduction and Fertility Supplement 35, 445-454.

Ball, B.A. (1988) Embryonic loss in mares: incidence, possible causes, and diagnostic considerations. Veterinary Clinic of North America 2, 263-290.

Ball, B.A., Altschul, M. \& Hillman, R.B. (1989) Luteal maintenance in mares after transfer of equine trophoblastic vesicles. Equine Veterinary Journal Supplement 8, 21-24.

Bergfelt, D.R. \& Ginther, O.J. (1986) Follicular populations following inhibition of FSH with equine follicular fluid during early pregnancy in the mare. Theriogenology 26, 733-747.

Bergfelt, D.R., Pierson, R.A. \& Ginther, O.J. (1989) Resurgence of the primary corpus luteum during pregnancy in the mare. Animal Reproduction Science 21, 261-270.

Ginther, O.J. (1983) The twinning problem: from breeding to day 16. Proceedings of the 29th Annual Conference of Association of Equine Practitioners, pp. 11-26.

Ginther, O.J. (1985a) Embryonic loss in mares: incidence, time of occurrence, and hormonal involvement. Theriogenology 23, 77-89.
Ginther, O.J. (1985b) Embryonic loss in mares: nature of loss after experimental induction by ovariectomy or prostaglandin $\mathrm{F}_{2 \mathrm{a}}$. Theriogenology 24, 87-98.

Ginther, O.J. (1986) Ultrasonic Imaging and Reproductive Events in the Mare. Cross Plains, WI Equiservices.

Ginther, O.J. \& Pierson, R.A. (1985) Ultrasonic evaluation of the corpus luteum of the mare. Theriogenology 23, 795-806.

Ginther, O.J., Bergfelt, D.R., Leith, G.S. \& Scraba, S.T. (1985) Embryonic loss in mares: incidence and ultrasonic morphology. Theriogenology 24, 73-86.

Irvine, C.H.G., Sutton, P., Turner, J.E. \& Mennick, P.E. (1990) Changes in plasma progesterone concentrations from Days 17 to 42 of gestation in mares maintaining or losing pregnancy. Equine Veterinary Journal 22, $104-106$.

Leith, G.S. \& Ginther, O.J. (1984) Characterization of intrauterine mobility of the early equine conceptus. Theriogenology 22, 401-408.

Woods, J.A., Bergfelt, D.R. \& Ginther, O.J. (1990) Effects of time of insemination relative to ovulation on pregnancy rate and embryonic-loss rate in mares. Equine Veterinary Journal 22, 410-415.

Received 11 March 1991 